\title{
Phosphorus Excretion Rate
}

National Cancer Institute

\section{Source}

National Cancer Institute. Phosphorus Excretion Rate. NCI Thesaurus. Code C150821.

A determination of the amount of phosphorus being excreted in a biological specimen over a defined period of time. 